\title{
Social, Environmental and Biological Determinants of Cerebral Palsy in Children with Intellectual Disabilities (ID) in India
}

\author{
Lakhan R 1
}

${ }^{1}$ Doctoral Candidate in Epidemiology, School of Health Science, College of Public Service, Jackson State University, 350, West Woodrow Wilson Drive, Jackson, MS 39213

\section{Chief Editor}

\section{Dr. Indrajit Banerjee}

Technical Editor

Dr. Nishida Chandrasekharan

Formatting Editor

Bedanta Roy

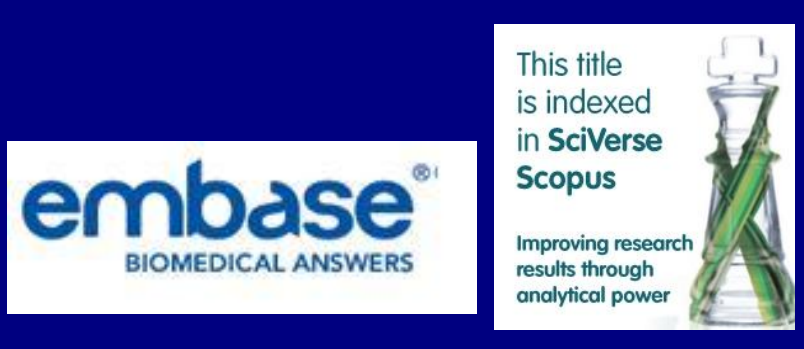

\section{Original Article}

\section{Corresponding Author}

Ram Lakhan, BMR, MS

Doctoral Candidate in Epidemiology

School of Health Science, College of Public Service

Jackson State University, 350

West Woodrow Wilson Drive

Jackson, MS 39213

Email Id: ramlakhan15@gmail.com

\section{Abstract}

\section{Background}

Cerebral palsy (CP) is a global public health problem affecting 2.12 to 2.45 per 1000 live birth across the world. Cerebral palsy is an upper motor neuron, non-progressive disorder commonly associated with intellectual disability. The presence of cerebral palsy effects person's overall life.

\section{Objectives}

This study primarily sought predictive capacity of social, environmental and biological determinants of CP in ID.

\section{Materials and Methods}

This is a cross-sectional study design. A total of 262 children, aged 3 to 18 years, with ID were assessed for cerebral palsy and diagnosed on basis of clinical examination in a community based rehabilitation project in Barwani, India. Information was collected by parent interviews, on social, environmental and biological determinants. A logistic regression model has been applied between determinants and $\mathrm{CP}$.

\section{Results}

Logistic regression demonstrated that likelihood of CP in ID children can be predicted on bases of their age (odd ratio = 0.856, $\mathrm{Cl} 95 \%-0.76-0.95$ ), intelligence quotients (IQ) (odd ratio $=0.782, \mathrm{Cl} 95 \%-0.73-0.83$ ) and family history of intellectual disabilities (odd ratio $=0.051, \mathrm{Cl} 95 \%-2.36$ 0.99) and epilepsy (odd ratio $=0.008, \mathrm{Cl} 95 \%-2.58-1.28$ ). Comorbid conditions of downs syndrome and epilepsy also predicts likelihood of CP in ID.

\section{Conclusion}

Likelihood of CP in ID children can be predicted by their age, IQ, family history of intellectual disability, epilepsy and comorbid conditions of downs syndrome and epilepsy. Gender, socio-economic status and population (tribal versus non-tribal) determinants have no predictive relation with $\mathrm{CP}$ in the group.

Keywords: cerebral palsy, intelligence quotient, intellectual disability, mental illness, epilepsy, downs syndrome, enuresis, behavior disorders

\section{List of Abbreviations:}

CP Cerebral palsy

IQ Intellectual quotient

ID Intellectual disability 
MI Mental illness

DS Down syndrome

FO Family history

CBR Community-based Rehabilitation

CBRW Community-based Rehabilitation worker

AGT Ashagram Trust

LAMI Low-and middle-income

DST Developmental Screening Test

VSMS Vineland Social Maturity Scale

DV Dependent variable

IV Independent variable

OR Odd ratio

NIMH-DDS National Institute for the Mentally Handicapped Developmental Screening Schedule

\section{Introduction}

Cerebral palsy (CP) is a global public health problem affecting 2.12 to 2.45 per 1000 live birth across the world 14. Population based studies conducted in India and China shows prevalence of CP from 2-2.8 per 1000 live births, which is very close to the prevalence in western settings 5 . Cerebral palsy is an upper motor neuron, non-progressive disorder. It is the most common physical disability among children6.

Classification of cerebral palsy is based on the involvement of body parts. Spastic hemiplegia refers to spasticity on one side of body such as an arm or an arm with a leg, spastic diplegia -is when lower limbs are involved with little or without involvement of upper body. Spastic quadriplegia is usually most serious form of CP that involves both upper and lower limbs. Ataxia is observed between $5-10 \%$ of all cases of CP. It affects balance, and muscle coordination of arms, legs and trunk. This type of CP is caused due to damage in cerebellar structure, while damage to cortical motor and underlying white matter is the cause for spastic CP. Athetoid/dyskinetic cerebral palsy happens due to damage in basal ganglia during brain development due to bilirubin encephalopathy and hypoxia7-9. Athetoid/dyskinetic form of cerebral palsy is commonly considered to be movement disorders. It exhibits both hypotonia and hypertonia and affects an individual's ability to control muscle tone10. Individuals with cerebral palsy have a higher mortality rate than the general population. In a study conducted on Californian population on cause of mortality in CP. The causes were attributed to brain cancer, respiratory, circulatory and digestive diseases 11.

Worldwide, $80 \%$ children with disabilities live in poverty and in resource poor settings. Thus the likelihood of CP in these areas is expected to be higher5. Children with $\mathrm{CP}$, especially in resource poor areas, are excluded from mainstream education12. Most often their disability restricts their mobility which becomes the greatest barrier in attending school. Further, it results into unemployment, and poor social life. Stigma and poor awareness on this disability in poor societies results in physical, social and attitudinal barriers for children with CP. They are restricted from interacting or playing with their peers and participation in social events13. This isolation affects child's self-esteem and enthusiasm for living. Lack of appropriate and accessible rehabilitation services in resource poor areas deprive $\mathrm{CP}$ children from maximizing their residual potential; this situation leads to more burden and stress for parents to raise a child with disability12-14.

This disorder is commonly associated with intellectual disability15. Learning and cognitive impairments are common with $\mathrm{CP}$. It is estimated that $45 \%$ children with $\mathrm{CP}$ have intellectual disabilities. Out of those approximately $25 \%$ have moderate (IQ < 50), and lower levels of ID16. Sensory such as hearing and visual impairments are also very common with $\mathrm{CP} 1$. Epilepsy and behavior problems are often associated with this condition. Epilepsy can affect up to $30 \%$ of children's population with CP16-18. Studies have proven association of cerebral palsy with low $I Q$, age and co-occurring conditions of epilepsy, behavior problems and social factors like poverty. However, there is limited information available about family history of intellectual disabilities and epilepsy as predictors of CP. It makes relevance to explore connections of social, environmental and biological factors in predicting the likelihood of cerebral palsy in children with ID.

This study was conducted under a community-based rehabilitation (CBR) project. Presently, CBRs approach of rehabilitation of disabled people is very popular in low-and middle-income countries (LAMI) and is being implemented in more than 90 countries worldwide19. People with cerebral palsy not only need medical attention and therapeutic services, but also other forms of services such as education, and equal opportunities for participation in social events and employment. Such needs of CP individuals living in poorer communities might also be met through CBR.

Objective:

This study attempted to find out predictive capacity of social, environmental and biological determinants of CP in ID.

\section{Material and Methods}

\section{Study design and duration:}

It was a Cross-Sectional of Eight years (July 15, 1999 to July 24, 2007).

\section{Sample size calculation:}

For $95 \%$ confidence interval, $\alpha=5 \%$, and allowable error $=$ $3 \%$ required sample size of 211 in total 262 population of ID children. In this study we included all 262 cases. 


\section{Study Site:}

This study was conducted in the poorest district of India of Madhya Pradesh state called Barwani $^{20}$ by a nongovernment organization Ashagram Trust (AGT), with the financial help of Action Aid in a CBR project. This project started in January 1999 and ended in December, 2010. This project was implemented in 63 villages of Barwani block of Barwani district. Half of the villages covered in the project have tribal population ${ }^{21}$. Approximately 64,000 people were covered in the project from the total population studied.

\section{Materials:}

NIMH-DDS, Developmental Screening Test (DST), Vineland Social Maturity Scale (VSMS), clinical examination and parent interviews are primary instruments used in the research.

\section{Methodology:}

The population of project villages was surveyed door to door for identifying children aged 3 to 18 years with intellectual disabilities. National Institute for the Mentally Handicapped Developmental Screening Schedule (NIMHDDS) was used for screening survey. This survey was conducted by community based rehabilitation workers (CBRWs) under supervision of a specialist in intellectual disabilities (RL). CBRWs underwent a week long training session on using an intellectual screening checklist, and on other aspects of survey including characteristics of ID. All identified cases were further assessed on two diagnostic tests, Developmental Screening Test (DST) and Vineland Social Maturity Scale (VSMS) for diagnosis ${ }^{22}$. A total of 262 cases were found to have ID. All 262 cases were further evaluated for CP by professionals in home, camp or clinical settings. Developmental, family, and demographic history was collected through interviewing parents after obtaining informed written or oral consent for research. Cases for other coexisting disorders were also evaluated. Collected information on social, environment and biological determinants was categorized into age, gender, IQ, family history of mental illness, intellectual disabilities, epilepsy and coexisting disorders epilepsy, downs syndrome, enuresis and behavior disorders.

\section{Ethical Committee Approval:}

Ethics committee comprising members of AGT, Action Aid and CBR team provided approval for study.

\section{Statistics:}

Statistical Package for the Social Sciences (SPSS) - 21 student version was used for data analysis. A correlational statistics was performed first to examine association of CP dependent variable (DV) with independent variables (IV). Pearson correlation was used with continuous IVs (age and IQ) and Spearman's with categorical variables ${ }^{23}$. Variables showing some sort of association with CP were analyzed as predictors of $\mathrm{CP}$ in logistic regression model through enter method. To reduce the effect of multicollinearity, parametric and non-parametric independent variables were analyzed separately in the model. CP was treated as a binary outcome in correlation and logistic regression. A logistic regression model is the best predictor of association between binary variables. This model has the ability to adjust independent scale variables with dichotomous dependent variables ${ }^{24}$. For reporting purpose, results are standardized in terms of percentage using following derivation (Odd Ratio -1$) \times 100=$ percentage $(\%)^{24}$.

\section{Results:}

82 (31.29\%) children were found with Cerebral Palsy in 262 children with ID. Table 1, illustrates their demographics, family history of illness, and comorbid disorders. Age wise distribution of CP cases in ID is mentioned in Table 2. Prevalence of $\mathrm{CP}$ was found to be higher among younger age group of children with ID (figure 1). Prevalence of CP was found to be considerably lower among children with higher IQ (figure 2).

Table 1: Distribution of Social, environmental and biological determinants of $\mathrm{CP}$

\begin{tabular}{|c|c|c|c|c|}
\hline \multicolumn{2}{|l|}{ Categories } & \multicolumn{2}{|c|}{$\begin{array}{l}\text { Cerebral Palsy } \\
\mathbf{n}=\mathbf{8 2}\end{array}$} & \multirow[t]{3}{*}{ Total } \\
\hline & & No & Yes & \\
\hline & & n (\%) & n (\%) & \\
\hline \multirow[t]{2}{*}{ Gender } & Female & 85 (32.44) & 39 (14.88) & $124(47.32)$ \\
\hline & Male & 95 (36.24) & $43(16.41)$ & 138 (52.67) \\
\hline \multirow{2}{*}{$\begin{array}{l}\text { Socio- } \\
\text { economic } \\
\text { status }\end{array}$} & Not poor & $38(14.50)$ & 22 (8.39) & $60(22.90)$ \\
\hline & Poor & $142(54.19)$ & $60(22.90)$ & 202 (77.09) \\
\hline \multirow{2}{*}{$\begin{array}{l}\text { Population } \\
\text { type }\end{array}$} & Tribal & $97(37.02)$ & 43(16.41) & $140(53.43)$ \\
\hline & $\begin{array}{l}\text { Non- } \\
\text { tribal }\end{array}$ & 83 (31.67) & 39 (14.88) & $122(46.56)$ \\
\hline \multirow{2}{*}{$\begin{array}{l}\text { F/O of } \\
\text { Mental } \\
\text { Illness }\end{array}$} & No & 155 (59.16) & $61(23.28)$ & $216(82.44)$ \\
\hline & Yes & $25(9.54)$ & $21(8.01)$ & 46 (17.55) \\
\hline \multirow{2}{*}{$\begin{array}{l}\text { F/O of } \\
\text { Intellectual } \\
\text { Disabilities }\end{array}$} & No & 161 (61.45) & $58(22.13)$ & 219 (83.58) \\
\hline & Yes & $19(7.25)$ & 24 (9.16) & $43(16.41)$ \\
\hline \multirow{2}{*}{$\begin{array}{l}\text { F/O of } \\
\text { Epilepsy }\end{array}$} & No & $154(58.77)$ & 46 (17.55) & $200(76.33)$ \\
\hline & Yes & $26(9.92)$ & 36 (13.74) & $62(23.66)$ \\
\hline \multirow{2}{*}{$\begin{array}{l}\text { Downs } \\
\text { Syndrome }\end{array}$} & No & 162 (61.83) & 81(30.91) & 243 (92.74) \\
\hline & Yes & $18(6.87)$ & $1(0.38)$ & $19(7.25)$ \\
\hline \multirow{2}{*}{$\begin{array}{l}\text { Behavior } \\
\text { Disorders }\end{array}$} & No & 36 (13.74) & $12(4.58)$ & $48(18.32)$ \\
\hline & Yes & $144(54.96)$ & $70(26.71)$ & $214(81.67)$ \\
\hline \multirow[t]{2}{*}{ Epilepsy } & No & $156(59.54)$ & 44 (16.79) & $200(76.33)$ \\
\hline & Yes & $24(9.16)$ & $38(14.50)$ & $62(23.66)$ \\
\hline \multirow[t]{2}{*}{ Enuresis } & No & $162(61.83)$ & $73(27.86)$ & 235 (89.69) \\
\hline & Yes & $18(6.87)$ & $9(3.43)$ & $27(10.30)$ \\
\hline
\end{tabular}


Table 2: Age wise distribution of CP cases in ID children

\begin{tabular}{|c|c|c|c|}
\multirow{2}{*}{$\begin{array}{c}\text { Age } \\
\text { (Years) }\end{array}$} & No & \multicolumn{2}{|c}{} \\
\cline { 2 - 3 } & $\mathbf{n}(\%)$ & $\mathbf{n}(\%)$ & \multirow{2}{*}{ Total } \\
\hline 3 & $6(2.29)$ & $22(8.39)$ & $28(10.68)$ \\
\hline 4 & $12(4.58)$ & $11(4.19)$ & $23(8.77)$ \\
\hline 5 & $12(4.58)$ & $4(1.52)$ & $16(6.10)$ \\
\hline 6 & $15(5.72)$ & $9(3.43)$ & $24(9.16)$ \\
\hline 7 & $13(4.96)$ & $5(1.90)$ & $18(6.87)$ \\
\hline 8 & $19(7.25)$ & $6(2.29)$ & $25(9.54)$ \\
\hline 9 & $13(4.96)$ & $5(1.90)$ & $18(6.87)$ \\
\hline 10 & $14(5.34)$ & $4(1.52)$ & $18(6.87)$ \\
\hline 11 & $10(3.81)$ & $3(1.14)$ & $13(4.96)$ \\
\hline 12 & $11(4.19)$ & $5(1.90)$ & $16(6.10)$ \\
\hline 13 & $11(4.19)$ & $2(0.76)$ & $13(4.96)$ \\
\hline 14 & $12(4.58)$ & $3(1.14)$ & $15(5.72)$ \\
\hline 15 & $6(2.29)$ & $2(0.76)$ & $8(3.05)$ \\
\hline 16 & $11(4.19)$ & $0(0.0)$ & $11(4.19)$ \\
\hline 17 & $4(1.52)$ & $0(0.0)$ & $4(1.52)$ \\
\hline 18 & $11(4.19)$ & $1(0.38)$ & $12(4.58)$ \\
\hline Total & $180(68.70)$ & $82(31.29)$ & $262(100.00)$ \\
\hline
\end{tabular}

Figure-1: Graph showing prevalence of CP with Age of ID Children

\section{Prevalence (\%) of CP with the Age of ID Children}

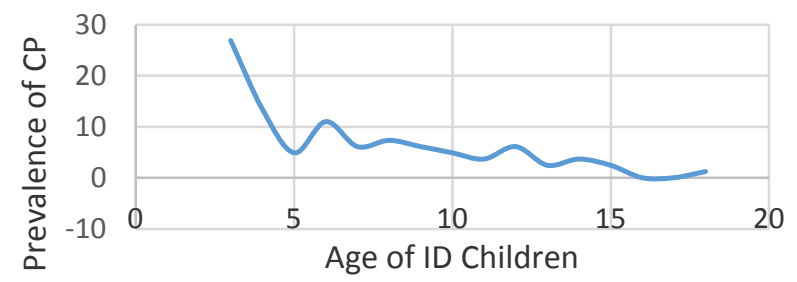

Figure-2: Graph showing prevalence of CP with IQ of ID Children

\section{Prevalence (\%) of CP with IQ of ID Children}

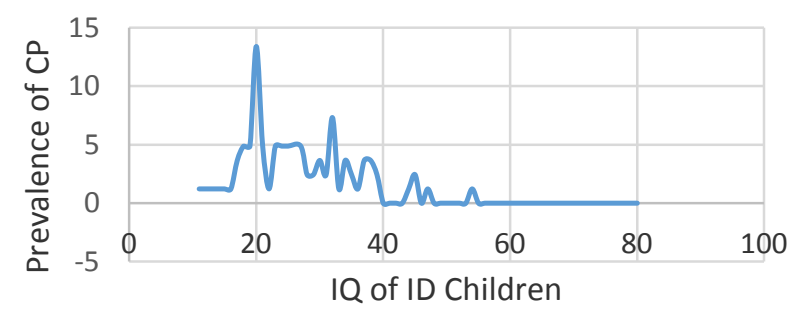

Table 3: Pearson and Spearman's correlation of CP with age, IQ, gender, socio-economic status, population, family history of mental illness, intellectual disabilities, epilepsy and epilepsy, downs syndrome, behavior disorders and enuresis

\begin{tabular}{|c|c|c|}
\hline Determinants (parametric) & Pearson rho & p-value \\
\hline Age & -0.0336 & 0.000 \\
\hline IQ & -0.710 & 0.000 \\
\hline Determinants (Non-parametric) & Spearman's rho & p-value \\
\hline Gender & -0.003 & 0.960 \\
\hline Socio-economic status & -0.063 & 0.309 \\
\hline Population Type & 0.013 & 0.828 \\
\hline F/O Mental Illness & 0.143 & 0.021 \\
\hline F/O Intellectual Disabilities & 0.234 & 0.000 \\
\hline F/O Epilepsy & 0.321 & 0.000 \\
\hline Downs Syndrome & -0.157 & 0.011 \\
\hline Behavior Disorders & 0.064 & 0.300 \\
\hline Epilepsy & 0.360 & 0.000 \\
\hline Enuresis & 0.015 & 0.811 \\
\hline
\end{tabular}

There is inverse association of CP with age (rho $=-0.0336$, $\mathrm{p}=0.001$ ) and IQ (rho $=-0.710, p=0.001)$. Family history of mental illness ( $r h o=0.143, p=0.021$ ), intellectual disabilities ( $r$ o $=0.234, p=0.001$ ) and epilepsy ( $r$ o $=0.321, p=0.001$ ) are positively associated. Similarly, comorbid conditions epilepsy was found to have positive correlation (rho = 0.361, $\mathrm{p}=0.001$ ) and Down's syndrome had an inverse correlation ( $r$ o $=-0.157, p=0.011$ ) with CP. Other factors such as gender, socio-economic status (poor versus not poor), population (tribal versus non-tribal), behavior disorders and enuresis are not associated $(p>0.05)$ with CP (table 3).

Independent factors: those found associated with CP irrespective of nature of relationship were selected for logistic regression. In our first analysis, we used parametric covariates, age and IQ in logistic model. Test of goodness fit Hosmer and Lemeshow $\mathrm{x}^{2}=9.140, \mathrm{p}=0.331$ did not reject null, which demonstrates that logistic regression model fits well in predicting occurrence of CP by age and IQ.

Table 4: logistic regression statistics of CP with age and IQ

\begin{tabular}{|c|c|c|c|c|c|c|c|}
\hline Predictors & B & SE & Wald / X & P value & $\begin{array}{c}\text { Exp (B) } \\
\text { / OR }\end{array}$ & $95 \%$ C.I. for Exp(B) \\
\hline $\begin{array}{c}\text { Constant ( } \\
\text { intercept) }\end{array}$ & 9.566 & 1.382 & 47.923 & 0.001 & 14277.011 & Lower & Upper \\
\hline $\begin{array}{c}\text { Age } \\
\text { IQ }\end{array}$ & -0.156 & 0.057 & 7.391 & 0.007 & 0.856 & 0.765 & 0.957 \\
\hline
\end{tabular}

Logistic regression equation is $Y=b_{0}+B_{1} X_{1}+B_{2} X_{2} \ldots \ldots$. Thus we obtained the following equation for this model $y=9.566$ - 0.156 (age) - 0.246 (IQ). The model demonstrates that increase of one unit (1 year) of age reduces likelihood of cerebral palsy by -0.156 . IQ is also inversely associated. As per the model, an increase of a unit of IQ decreases chances of $\mathrm{CP}$ by -0.246 . The Odds ratio for age $=0.856$ 
interpretation demonstrates that an increase of 1 year age, decreases likelihood of $\mathrm{CP}$ by $14.4 \%$. Odds ratio for $\mathrm{IQ}=$ 0.782 means likelihood of CP decreases by $21.8 \%$ (table 4 ). In the second analysis, we applied logistic regression with binary IVs. Test of goodness fit Hosmer and Lemeshow $\mathrm{x}^{2}=$ $3.873, p=0.423$ did not reject null, which demonstrates that the logistic regression model fits well in predicting occurrence of CP by family history of ID, Epilepsy and by presence of Down's syndrome and epilepsy in the individual.

Table 5: Logistic regression statistics of CP with family history of mental illness, intellectual disabilities, epilepsy and comorbid conditions of Down's syndrome and epilepsy

\begin{tabular}{|c|c|c|c|c|c|c|c|}
\hline $\begin{array}{c}\text { Predicto } \\
\text { rs }\end{array}$ & B & SE & $\begin{array}{c}\text { Wald } \\
/ \mathbf{X}^{2}\end{array}$ & $\begin{array}{c}\text { P } \\
\text { value }\end{array}$ & $\begin{array}{c}\text { Exp } \\
\text { (B) } \\
\text { /OR }\end{array}$ & $\begin{array}{c}95 \% \text { C.I. for } \\
\text { Exp(B) }\end{array}$ \\
\hline Constant & -1.473 & 0.204 & $\begin{array}{c}52.32 \\
2\end{array}$ & 0.000 & 0.22 & Lower & Upper \\
\hline $\begin{array}{c}\text { F/O } \\
\text { mental } \\
\text { illness }\end{array}$ & 0.084 & 0.447 & 0.036 & 0.850 & $\begin{array}{c}1.08 \\
8\end{array}$ & 0.453 & 2.613 \\
$\begin{array}{c}\text { F/O } \\
\text { mental } \\
\text { retardati } \\
\text { on }\end{array}$ & 0.859 & 0.440 & 3.815 & 0.051 & $\begin{array}{c}2.36 \\
2\end{array}$ & 0.997 & 5.595 \\
$\begin{array}{c}\text { F/O } \\
\text { epilepsy }\end{array}$ & 0.950 & 0.357 & 7.082 & 0.008 & 2.58 & 1.284 & 5.204 \\
$\begin{array}{c}\text { Downs } \\
\text { Syndrom } \\
\text { e }\end{array}$ & -2.120 & 1.111 & 3.643 & 0.056 & 0.12 & 0.014 & 1.059 \\
\hline \begin{tabular}{c} 
Epilepsy \\
\hline
\end{tabular} & 1.214 & 0.353 & 11.80 & 0.001 & 3.36 & 1.685 & 6.733 \\
\hline
\end{tabular}

We obtained following equation for this model, $y=-1.473+$ $0.859(F / 0$ MR) + 0.950 (F/O Epilepsy) +1.214 (epilepsy) 2.124(downs Syndrome). The model demonstrates that increase of one unit of family history of intellectual disabilities increases likelihood of CP by 0.859 and epilepsy by 0.950 . Increase of Epilepsy by one unit as comorbid condition also increases likelihood of CP by 1.214 , while thre other comorbid condition viz. Down's syndrome was inversely associated. The increase of one unit of DS reduces likelihood of CP by -2.120 . In standardized terms, family history of intellectual disabilities $\mathrm{OR}=2.362$ indicates $136.2 \%$ increase in likelihood of $\mathrm{CP}$, and family history of epilepsy $\mathrm{OR}=2.585$, increases likelihood of CP by $158.5 \%$. Comorbid condition of epilepsy $\mathrm{OR}=3.368$ increases likelihood of $\mathrm{CP}$ by $236.8 \%$, while Down's syndrome OR $=0.120$ decreases likelihood of CP by $88 \%$ (table 5 ).

\section{Discussion:}

We classified our study variables in to social, environmental and biological categories. However, it is difficult to have such discrete categorization because some variables overlap between categories. Findings are discussed in light of international scenario on $\mathrm{CP}$ and in relevance of LAMI countries.

\section{Cerebral palsy and social determinants:}

In our study, $22.90 \%$ CP children belong to poor socioeconomic status while $8.39 \%$ are not that poor. Poor in study are those who were solely dependent on manual labor while not poor are little better off than poor as they have few cattle and few families own little agricultural land. Studies conducted worldwide shown association of cerebral palsy with poverty specially in LAMI countries ${ }^{5}$, but our findings did not match fairly with the variables selected in the analysis of poor versus not poor. However, in correlation with other studies these results should conform, because the overall population studied here was poor. $16.41 \%$ CP children belong tribal population, while $14.88 \%$ are non-tribal. It can be stated that tribal population is more vulnerable to $\mathrm{CP}$, and this could be attributed to poverty and lack of health facilities in this region; however we are unable to support this observation due to lack of research evidence in this area.

\section{Cerebral palsy and environmental determinants:}

$8.01 \%$ of children with CP have family history of mental illness, $13.74 \%$ have family history of epilepsy and $9.16 \%$ have history of intellectual disabilities. There is a strong genetic influence and this has been reported on likelihood of developing CP in worldwide population studies ${ }^{7,25}$, which validates our findings. However, in prediction models genetic heterogeneity and multifactorial environmental influences are incorporated ${ }^{26}$. In Asian consanguineous marriages cerebral palsy is inherited high as $50 \%$ as autosomal recessive trait ${ }^{7}$.

\section{Cerebral palsy and biological determinants:}

Findings of this study are consistent with other studies in explaining association of cerebral palsy with $\mathrm{IQ}^{16}$, and cooccurring epilepsy ${ }^{18}$. A study conducted in Sweden demonstrated an association between CP and epilepsy. In that study children with tetraplegia CP has early onset of epilepsy, while many children with hemiplegia developed partial seizures later on. In this study prevalence of epilepsy was found to be higher among those had cognitive dysfunction or low level of intelligence (IQ). Thus study also makes connections between IQ and epilepsy in CP. According to that study, CP and its etiology can predict development of epilepsy and its outcome ${ }^{16}$. Studies conducted in European countries showed that generalized and partial epilepsy are more common in $\mathrm{CP}^{27}$.

In the age group of 3 to 6 years, children with ID have $9.16 \%$ to $10.68 \% \mathrm{CP}$. This percentage reduces in the age group 7 10 years of age to $6.87 \%$; at 11 years $4.96 \%$, at 15 years $3.05 \%$, down $1.52 \%$ at 17 and $4.96 \%$ for 18 years. Our results indicates lower prevalence rate of $\mathrm{CP}$ in older age group of children. The same tendency of lower prevalence in older age group of children was observed in a prevalence study conducted in a similarly impoverished population of another LAMI country, Nepal ${ }^{28}$. Emerson et al. (2012) based on World Bank report of 2010, reported in their editorial article that over $10 \%$ of children would die before their fifth birthday in LAMI countries ${ }^{29-30}$. Children with ID in such countries are also reported at higher risk of denial for health 
care service $^{31}$. This may be the reason for lower prevalence among older age group of children with $\mathrm{CP}$.

Occurrence of CP is not found significantly different between male and female children. In our study $16.41 \%$ male and $14.88 \%$ female with ID have CP. A study conducted in South America showed similar results ${ }^{32}$. Down's syndrome was found to be associated with $0.38 \%$ and enuresis in $3.43 \%$ of the CP population in our study. Down's syndrome and enuresis are common genetic and biological conditions associated with CP. However, presence of enuresis cannot predict occurrence of $\mathrm{CP}$ in ID population. Pakula AT et al. (2009) in their review article of prevalence studies conducted worldwide reported that urogenital disorders including enuresis, and genetic disorders are common, but they are not essentially predictors of $\mathrm{CP}$ in $\mathrm{ID}^{25}$.

\section{Conclusion:}

This study has public health implications in predicting the likelihood of cerebral palsy in children with ID on bases of their IQ, age, family history of intellectual disabilities, epilepsy, and co-existing disorders of epilepsy and Down's syndrome. Further studies are needed to explore reasons of low frequency (prevalence) of CP in older age groups as compared to younger children with ID. However, these findings can guide professionals involved in assessment and care for cerebral palsy and intellectual disabilities. They can provide better guidance and appropriate referrals for services to the clients with CP. Public health agencies and practitioners may incorporate findings of this study in designing programs on $\mathrm{CP}$.

\section{Limitation of the Study:}

Cerebral palsy is classified into different types. In this study we covered all types of $\mathrm{CP}$ in one category. Analysis with different types of $\mathrm{CP}$ with study variables would have enriched research findings.

\section{Further Scope of Study:}

Analysis with different types of $\mathrm{CP}$ associated with various levels of socio -economic status, parental education and different level of family pedigree (first, second and third) and different types of epilepsy would enhance the predictive model of cerebral palsy. Environmental factors such as smoking, drinking, early age pregnancy and consanguineous marriages are very common factors in the studied population, and consideration of those ought to be included in future research.

\section{Acknowledgment:}

The author sincerely thanks Ashagram Trust for allowing him to conduct this research. He further thanks the children with $\mathrm{CP}$, their parents, CBRWs and CBR team for their participation and Action Aid for their financial support.

\section{Conflict of interest:}

The author does not have any conflict of interest arising from this study.

\section{What this Study adds:}

This study demonstrates that the likelihood of Cerebral Palsy can be predicted by the age and IQ of children with ID. Family history of intellectual disabilities and epilepsy are also strong predictors of CP among children with intellectual disabilities.

\section{References:}

1. Odding E, Roebroeck ME, Stam HJ. The epidemiology of cerebral palsy: incidence, impairments and risk factors. Disability Rehabilitation 2006; 28(4):183-91.

2. Arneson CL, Durkin MS, Benedict RE, Kirby RS, YearginAllsopp M, Naarden Braun VK, et al. Prevalence of Cerebral Palsy: Autism and Developmental Disabilities Monitoring Network, Three Sites, United States, 2004. Disability and Health Journal 2009; 2(1): 45-48.

3. Bhasin TK, Brocksen S, Avchen RN, Naarden Braun VK. Prevalence of four developmental disabilities among children aged 8 years - Metropolitan Atlanta Developmental Disabilities Surveillance Program, 1996 and 2000. MMWR. Surveillance Summaries 2006; $55(1): 1-9$. Accessed on $9^{\text {th }}$ July 2013 (available online URL: http://www.cdc.gov/mmwr/PDF/ss/ss5501.pdf ).

4. Paneth $\mathrm{N}$, Hong $\mathrm{T}$, Korzeniewski $\mathrm{S}$. The descriptive epidemiology of cerebral palsy. Clinics in Perinatology 2006; 33(2): 251-267.

5. Gladstone M. A review of the incidence and prevalence, types and aetiology of childhood cerebral palsy in resource-poor settings. Annals of Tropical Pediatrics 2010; 30 (3):181-96.

6. Koman LA, Peterson-Smith B, Shilt JS. Cerebral palsy. The Lancet 2004; 363 (9421): 1619-31.

7. McHale DP, Jackson AP, Campbell DA, Levene MI, Corry $P$, Woods CG et al. A gene for ataxic cerebral palsy maps to chromosome. European Journal of Human Genetics 2000; 8 (4): 267-272.

8. Cheney PD. Pathophysiology of the corticospinal system and basal ganglia in cerebral palsy. Mental Retardation and Developmental Disabilities Research Reviews 1997; 3 (2): 153-167.

9. Hou M, Zhao J, Yu R. Recent advances in dyskinetic cerebral palsy. World Journal of Pediatrics 2006; 2(1): 23-28.

10. O'Shea MT. Diagnosis, treatment, and prevention of cerebral palsy in near-term/term infants. Clinical Obstetrics Gynecology 2008; 51(4): 816-828.

11. David S, William C, Robert S. Causes of excess mortality in cerebral palsy. Developmental Medicine and Child Neurology 1999; 41(9): 580-585.

12. Lakhan R. Inclusion of children with intellectual and multiple disabilities: a community based rehabilitation approach, India. Journal of Special Education and Rehabilitation 2013; 14 (1):79-97.

13. Mihaylov SI, Jarvis SN, Colver AF, Beresford B. Identification and description of environmental factors 
that influence participation of children with cerebral palsy. Developmental Medicine and Child Neurology 2004; 46(5): 299-304.

14. Natasha CJ, Daniela DR. Parents of Children with Developmental Disabilities. Journal of Special Education and Rehabilitation 2013; 14 (1):7-13.

15. Lakhan R. The Coexistence of Psychiatric Disorders and Intellectual Disability in Children Aged 3-18 Years in the Barwani District, India. ISRN Psychiatry 2013; Article ID 875873. (http://dx.doi.org/10.1155/2013/875873)

16. Carlsson M, Hagberg G, Olsson I. Clinical and aetiological aspects of epilepsy in children with cerebral palsy. Devolvement Medicine Child Neurology 2003; 45(6):371-76.

17. McDermott $S$, Coker AL, Mani S, Krishnaswami S, Nagle RJ, Barnett-Queen LL, Wuori DF. A population-based analysis of behavior problems in children with cerebral palsy. Journal of Pediatric Psychology 1996; 21(3):44763.

18. Bruck I, Antoniuk SA, Spessatto A, Bem RS, Haysberger $\mathrm{R}$, Pacheco CG. Epilepsy in children with cerebral palsy. Arquivos de neuro psiquitria 2001; 59(1): 35-9.

19. Robertson J, Emerson E, Hatton C, Yasmy MT. Efficacy of Community-Based Rehabilitation for Children with or at Significant Risk of Intellectual Disabilities in Low- and Middle-Income Countries: A Review. Journal of Applied Research in Intellectual Disabilities 2012; 25 (2): 143154.

20. Report of the Task Force. Identification of Districts for Wage and Self-Employment Programs, Planning Commission, Bengal Offset Works, New Delhi, India, 2003. Accessed on $9^{\text {th }}$ July 2013 (available online URL: http://planningcommission.nic.in/reports/publications/ tsk_idw.pdf).

21. Lakhan R. Effectiveness of Community-Based Rehabilitation against Institutional Based Rehabilitation of Persons with Mental Retardation in a Tribal District of Madhya Pradesh, India. Journal of the Psychological Researches 2009; 53 (1): 60-66.

22. Bharat Raj J, Vineland Social Maturity Scale-Indian Adaptation: Enlarged Version, Swayamsiddha Prakashanam, Mysore, India, 1992.

23. Sathian B. Methodological Rigors in Medical Journals from Developing Countries: An Appraisal of the Scenario in Asia. Nepal Journal of Epidemiology 2011; 1(5): 141-43.

24. LaValley MP. Logistic Regression. Circulation 2008; 117 (18): 2395-9.

25. Pakula AL, Nardeen Barun KV, Yeargin-Allsopp $M$. Cerebral Palsy: Classification and Epidemiology. Physical Medicine and Rehabilitation Clinics of North America 2009; 20(3): 425-452. doi:10.1016/j.pmr.2009.06.001
26. Schaefer GB. Genetic Considerations in Cerebral Palsy. Seminars in Pediatric Neurology 2008; 15 (1): 21-26. DOI:10.1016/j.spen.2008.01.004

27. Wallace SJ. Epilepsy in cerebral palsy. Developmental Medicine and Child Neurology 2001; 43(10):713-7.

28. Karkee R, Yadav BK, Chakravartty A, Shrestha DB. The prevalence and characteristics of disability in Eastern Nepal. Kathmandu University Medical Journal 2008; 6 (1): 94-97.

29. Emerson E, Yasamy MT, Shekhar S. Editorial Scaling up Support for Children with developmental Disabilities in Low-and Middle-Income Countries. Journal of Applied Research in Intellectual Disabilities 2012; 25(2): 96-98.

30. World Bank (2010) World Development Report 2010: Development and Climate Change. World Bank, Washington.

31. Emerson E, McConkey R, Walsh P, Felce D. Intellectual disability in a global context. Journal of Policy and Practice in Intellectual Disability 2008; 5(2): 79-80.

32. Pfeifer LI, Silva DB, Funayama CA, Santos JL. Classification of cerebral palsy: association between gender, age, motor type, topography and Gross Motor Function. Arquivos de neuro psiquitria 2009; 67(4):1057-61.

\begin{tabular}{|l|l|}
\hline \multicolumn{2}{|c|}{ Article Information } \\
\hline \multicolumn{2}{|c|}{ Article history } \\
\hline Received & $29^{\text {th }}$ Jan 2013 \\
\hline Received in revised form & $3^{\text {rd }}$ June 2013 \\
\hline Accepted & $3^{\text {rd }}$ August 2013 \\
\hline
\end{tabular}

